Jurnal Teknologi, 40(A) Jun. 2004: 79-96

(C) Universiti Teknologi Malaysia

\title{
TAHAP KEFAHAMAN DAN KEBERKESANAN SKIM AMALAN PENINGKATAN KUALITI DI INDUSTRI KECIL DAN SEDERHANA
}

\author{
BABA MOHD DEROS ${ }^{1}$, AZMI HASSAN ${ }^{2} \&$ SARIMAH OTHONG $^{3}$
}

\begin{abstract}
Abstrak. Persaingan sengit pasaran, kepelbagaian produk, kitaran hayat produk singkat dan memenuhi citarasa serta keperluan pelanggan telah mendorong syarikat-syarikat supaya sentiasa berusaha meningkatkan kualiti dan mengurangkan kos pembuatan produk mereka. Kertas kerja ini membincangkan hasil kajian penilaian tahap kefahaman Industri Kecil dan Sederhana (IKS) mengenai sistem pengurusan kualiti APK dan implikasi pengamalan syarikat dalam meningkatkan daya saing di dalam pasaran sedia ada dan pasaran baru. Kajian ini akan melihat samada IKS sudah bersiap sedia untuk menghadapi cabaran di dalam era persaingan global dan mampu menyesuaikan diri dengan cara baru dalam pengurusan perniagaan. Selain dari itu, IKS akan dinilai dalam aspek inisiatif untuk meningkatkan tahap pencapaian dengan memberi penekanan kepada aktiviti-aktiviti peningkatan kualiti bagi penghasilan produk dan perkhidmatan berkualiti yang dapat diterima oleh pasaran antarabangsa. Kertas kerja ini juga akan membincangkan status perlaksanaan sistem pengurusan kualiti setelah memasuki program Amalan Peningkatan Kualiti (APK) yang telah dilancarkan oleh SIRIM pada tahun 1988. Untuk mengumpul maklumat yang lebih tepat, satu kajian soal selidik telah dijalankan. Kerta kerja ini akan memaparkan keputusan kajian soal selidik terhadap perlaksanaan sistem pengurusan kualiti di IKS. Hasil kajian telah menunjukkan hanya 57 peratus daripada pihak pengurusan IKS yang menyertai program telah memahami konsep APK dengan baik. Syarikatsyarikat lain masih lagi berada di tahap yang lemah.
\end{abstract}

Kata kunci: Industri Kecil dan Sederhana, Amalan Peningkatan Kualiti, persaingan, pembuatan

Abstract. Intense market competition, product varieties, short product life cycle, and fulfilling customer needs and desires have prompted many companies to continuously improve their product quality and lower the manufacturing cost. This paper describes the research findings on the evaluation of the level of understanding of Small and Medium Sized Industry (SMIs) with regards to quality management systems, particularly, the Quality Improvement Practice (QIP), and its implications on the implementation in order to improve competitiveness in current and new market. The research will determine whether the SMIs are ready to face the challenges in the era of global competition and able to adapt to new ways of managing business. It will also determine the initiative of SMIs in improving their level of achievement by emphasizing on quality improvement activities to produce quality products and services acceptable at the international market. This paper also discusses the quality management system implementation status after participating in the QIP launched by SIRIM in 1988. In order to gather more accurate information, a survey was conducted to elicit the required information. This paper will present the result of the survey on quality management system in SMIs. The result

$1 \& 2$ Fakulti Kejuruteraan, Universiti Kebangsaan Malaysia, 43600 Bangi, Selangor.

E-mail: hjbaba@vlsi.eng.ukm.my

3 SIRIM Berhad, 40000 Shah Alam, Selangor, Malaysia. 
indicates that only 57 percent of the SMIs that participated in the program had a good understanding on the QIP concept, while others still have a low level of understanding.

Keywords: Small and Medium Industry, Quality Improvement Practice, competition, manufacturing

\subsection{INTRODUCTION}

Peningkatan keantarabangsaan, globalisasi dan prestasi ekonomi tempatan, serantau dan dunia telah mengubah persekitaran persaingan pasaran di peringkat nasional dan antarabangsa. Keadaan persekitaran yang baru serta mencabar ini telah mendorong ramai pengurusan atasan korporat yang berpandangan jauh untuk menilai semula strategi kebolehsaingan dan amalan pengurusan mereka. Ini bertujuan untuk meningkatkan prestasi organisasi, kualiti dan kecekapan pengurusan kewangan. Pengurusan kualiti menyeluruh (TQM) adalah satu falsafah pengurusan yang dapat mengintegrasikan strategi, amalan pengurusan dan prestasi kewangan untuk mewujudkan organisasi yang sentiasa mengamalkan peningkatan berterusan bagi mengekalkan serta mempertingkatkan prestasi. Hakikatnya, IKS juga tidak terkecuali daripada tekanan-tekanan ini. Untuk terus wujud dan berkembang maju dalam persaingan global dan peningkatan permintaan pelanggan, IKS mestilah mampu menunjukkan kemampuan mereka untuk memahami dan menilai keadaan persekitaran persaingan perniagaan dengan segera, seperti pesaing-pesaing mereka yang terdiri daripada organisasi-organisasi besar di peringkat antarabangsa.

Kualiti produk dan servis yang dikeluarkan kepada pelanggan merupakan elemen perniagaan yang amat penting kepada kejayaan syarikat kerana ia akan mempengaruhi permintaan ke atas produk dan servis tersebut. Menurut Heizer dan Render [1], kualiti memainkan peranan penting di dalam sesebuah syarikat kerana ia memberi kesan kepada reputasi syarikat, kos dan bahagian pasaran, tanggungjawab ke atas produk (product liability) dan implikasi antarabangsa. Sistem pengurusan kualiti pula merupakan satu sistem atau mekanisme untuk mengekalkan dan mempertingkatkan kualiti secara berterusan bagi memenuhi keperluan pelanggan. Ia meliputi polisi, odit dan semakan, serta tindakan pembetulan dan pencegahan.

Menurut Hashim [2], tujuan sistem pengurusan kualiti adalah untuk:

(1) memastikan keperluan pelanggan dipenuhi secukupnya pada setiap masa dan setiap kali.

(2) memberi panduan kepada pekerja dan juga memastikan setiap pekerja mengetahui Apa (What), Mengapa (Why), Di mana (Where), Siapa (Who) dan Bagaimana (How) (i.e. $4 \mathrm{~W} 1 \mathrm{H})$ di dalam melaksanakan sesuatu tugas.

(3) mengurangkan dan mencegah kerosakan, kesilapan dan kecacatan dalam melaksanakan sesuatu tugas.

(4) mengeluarkan produk yang berkualiti dengan konsisten.

(5) meninggikan daya kecekapan pengeluaran. 


\subsection{KAJIAN AWAL AMALAN PENGURUSAN KUALITI}

Rajah 1 memaparkan data kajian yang telah dijalankan oleh Idris dan Idris [3] ke atas 650 buah syarikat yang telah menerima persijilan ISO 9000. Lazimnya, syarikat yang telah memperolehi persijilan ISO 9000 mempunyai kecenderungan yang lebih tinggi untuk mengamalkan aktiviti-aktiviti peningkatan kualiti. Ini kerana ISO 9000 adalah merupakan langkah asas di dalam usaha untuk melaksanakan amalan pengurusan kualiti menyeluruh (TQM).

Merujuk kepada Rajah 1, didapati kebanyakan aktiviti pengurusan kualiti yang diamalkan secara meluas oleh syarikat-syarikat yang telah menerima persijilan ISO 9000 ialah seperti kaedah penyelesaian masalah (72\%), program kesedaran kualiti (62\%), kaedah persampelan (62\%), 5S (55\%), kawalan proses secara statistik, SPC (48\%) dan penyenggaraan produktif menyeluruh, TPM (44\%). Manakala, aktivitiaktiviti seperti kumpulan kawalan kualiti, QCC (23\%) dan pengurusan kualiti menyeluruh, TQM (21\%), masih lagi kurang diamalkan. Dalam satu kajian lain, Aziz et al., [4] mendapati kaedah persampelan merupakan teknik yang masih meluas digunakan oleh industri di Malaysia untuk menilai tahap kualiti produk atau servis dan bukannya melalui pemeriksaan 100\%. Fakta ini adalah selari dengan hasil kajian oleh Musa [5] yang mendapati hanya 43\% syarikat telah menggunakan kaedah pemeriksaan 100\% untuk menentukan tahap kualiti produk atau servis. Data-data daripada kajian-kajian lepas menunjukkan sistem pengurusan kualiti yang diamalkan oleh syarikat-syarikat di Malaysia masih lagi di peringkat permulaan. Ia hanya meliputi teknik-teknik tertentu untuk memastikan tahap kualiti produk dan servis dan tidak diamalkan secara komprehensif.

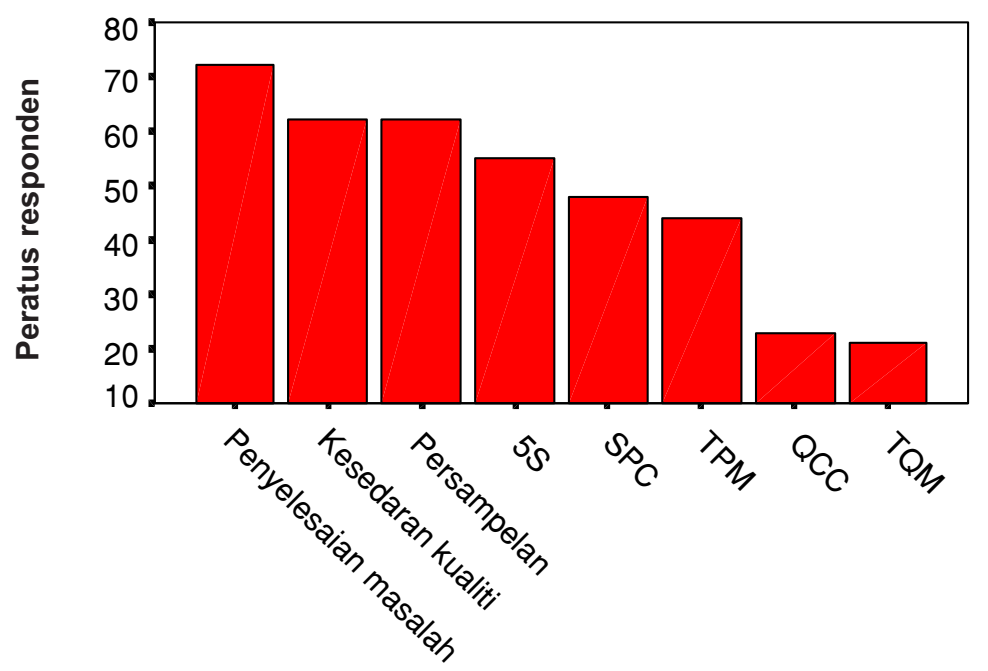

Rajah 1 Aktiviti pengurusan kualiti oleh syarikat yang mempunyai sijil ISO 9000 


\subsection{DEFINISI DAN KEPENTINGAN IKS}

\subsection{Definisi Untuk IKS}

Biasanya, sesebuah sistem perniagaan terdiri daripada campuran syarikat-syarikat kecil, sederhana dan besar. IKS boleh didefinisikan menurut beberapa faktor dan kriteria seperti lokasi, saiz, umur, struktur organisasi, bilangan pekerja, jumlah jualan tahunan, dan lain-lain [5,6]. Kini, terdapat pelbagai definisi yang diberikan untuk IKS, samada dengan menggunakan kaedah kuantitatif, kualitatif ataupun kedua-duanya sekali. Jadual 1 menunjukkan ringkasan definisi-definisi yang digunakan untuk IKS yang terlibat di sektor pembuatan di beberapa buah negara terpilih. Di dalam kaedah kuantitatif, bilangan pekerja merupakan kayu pengukur yang sering digunakan untuk menentukan saiz sesebuah syarikat di kebanyakan negara [7,8,9]. Penulis telah menggunapakai definisi IKS yang dikeluarkan oleh SMIDEC [10] pada tahun 1998 seperti di dalam Jadual 1 semasa menjalankan kajiselidik ini.

Jadual 1 Ringkasan definisi-definisi yang digunakan untuk IKS

\begin{tabular}{|c|c|c|c|}
\hline Negara & Sektor & $\begin{array}{l}\text { Bilangan } \\
\text { pekerja }\end{array}$ & Ukuran-ukuran lain \\
\hline Australia & Pembuatan & $<100$ & \\
\hline Canada & Pembuatan & $<500$ & \\
\hline Republik Rakyat China & $\begin{array}{l}\text { Bergantung } \\
\text { pada industri }\end{array}$ & $\begin{array}{l}\text { Biasanya } \\
\quad<100\end{array}$ & \\
\hline Indonesia & & $<100$ & \\
\hline Jepun & Pembuatan & $<300$ & Harta $く ¥ 100$ million \\
\hline Korea & Pembuatan & $<300$ & \\
\hline Malaysia & Pembuatan & $<150$ & Nilai jualan $<$ RM25 million \\
\hline Filipina & & $<200$ & Harta $<$ P40 million \\
\hline Singapura & Pembuatan & & Harta tetap $<\mathrm{S} \$ 12$ million \\
\hline Taiwan & Pembuatan & & $\begin{array}{l}\text { Modal berbayar }<\text { NT } \$ 40 \text { million } \\
\text { dan jumlah harta }<\text { NT } \$ 120 \text { million }\end{array}$ \\
\hline Amerika Syarikat & & $<500$ & \\
\hline \multicolumn{4}{|c|}{$\begin{array}{l}\text { Nota: } ¥=\text { Yen Jepun, RM=Ringgit Malaysia, } \mathrm{P}=\text { Peso Filipina, } \mathrm{S} \$=\text { Singapore Dollar, } \\
\text { NT } \$=\text { New Taiwanese Dollar }\end{array}$} \\
\hline
\end{tabular}




\subsection{Kepentingan IKS}

Di kesatuan Eropah, IKS mewakili lebih 95\% daripada jumlah bilangan syarikat berdaftar dan memberikan peluang pekerjaan kepada lebih 50\% daripada jumlah tenaga kerja [13] dan 65\% daripada jumlah nilai pusingan perniagaan [14]. Manakala di Australia, 90\% daripada syarikat perniagaan tergolong di bawah kategori IKS dan menyediakan pekerjaan kepada 50\% daripada jumlah tenaga kerja [15]. DiJepun, 75\% daripada jumlah pekerjaan di sektor pembuatan ditawarkan oleh IKS yang mempunyai kurang dari 300 pekerja [14].

Di Malaysia, IKS juga memainkan peranan yang penting di dalam sistem perniagaan dan membentuk satu komponen penting dalam peningkatan ekonomi. Ia boleh dikategorikan kepada 4 sektor utama iaitu, perniagaan am, pembuatan, pengeluaran bahan-bahan mentah asas dan pertanian. Lebih 90\% daripada keseluruhan organisasi pembuatan dikelaskan di bawah kategori IKS [16-19]. Oleh kerana itu, IKS memainkan peranan yang sangat penting untuk menyokong dan mengekalkan agenda perindustrian negara bagi mencapai taraf negara maju. Perkembangan sektor IKS dibantu oleh 18 kementerian dan lebih daripada 60 agensi kerajaan [20]. Pada tahun 2000, IKS bertanggungjawab menyediakan 31.2\% daripada jumlah pekerjaan di dalam sektor pembuatan dan menyumbangkan $82.6 \%$ dalam bentuk penjanaan pendapatan serantau melalui pengekspotan ke luar negara atau sebagai gantian kepada barangan impot [7]. Manakala, menurut Shan [17], IKS menyumbang 20\% daripada jumlah eksport negara di dalam sektor pembuatan dan $80 \%$ daripada perolehan dalam negara.

Sumbangan IKS dalam sektor pembuatan adalah penting seperti yang ditunjukkan oleh Pengeluaran Kasar Domestik (GDP). SMI Development Plan [21] dan Hashim dan Wafa [7] melaporkan, pada tahun 1991, IKS di sektor pembuatan telah menyumbangkan 20\% (iaitu RM4.3 bilion) kepada GDP dan sumbangan ini telah meningkat kepada 40\% (iaitu RM21.4 bilion) pada tahun 2000. Menjelang tahun 2020, diramalkan sumbangan IKS kepada GDP akan mencapai tahap 50\% (iaitu RM120 bilion). Data-data ini menunjukkan bahawa IKS memberikan sumbangan yang besar ke arah pencapaian ekonomi sesebuah negara dan dianggap sebagai satu sumber untuk menyediakan peluang pekerjaan baru [22].

\subsection{Skim Amalan Peningkatan Kualiti}

Menyedari peranan dan kepentingan IKS dalam pembangunan dan pengembangan ekonomi negara serta peluang pasaran global yang boleh diterokai, agensi-agensi kerajaan seperti Standards and Industrial Research Institute of Malaysia (SIRIM) dan National Productivity Corporation (NPC) telah menyediakan pelbagai program, kemudahan dan latihan teknikal untuk mempromosikan aktiviti-aktiviti peningkatan kualiti dan produktiviti kepada IKS. Di dalam program ini, pihak IKS didedahkan dengan teknik dan pendekatan terkini mengenai kualiti dan produktiviti melalui seminar, perundingan dan bengkel [23]. Pada tahun 1988, SIRIM telah melancarkan 
skim Amalan Peningkatan Kualiti (APK) khusus untuk membantu IKS bagi mempertingkatkan prestasi produk dan servis supaya lebih berdaya maju dan berdaya saing [24]. Skim ini diwujudkan sebagai usaha untuk mempromosikan kesedaran mengenai ISO 9000 di kalangan IKS. Ianya setaraf dengan sistem pengurusan kualiti ISO 9000 tetapi dengan beberapa kelonggaran tertentu sesuai dengan objektif skim untuk membantu IKS menyediakan asas sistem kualiti di samping memastikan peningkatan pelaksanaannya dari semasa ke semasa [25].

Dari perbincangan di atas, penulis membuat rumusan bahawa IKS memainkan peranan yang besar dan penting untuk menyokong kestabilan ekonomi dan kebolehsaingan sesebuah negara bagi menghadapi dan mengatasi cabaran antarabangsa dan global.

\subsection{OBJEKTIF KAJIAN}

Matlamat utama kajian ini ialah untuk:

(i) Mengenal pasti keadaan pengurusan kualiti di IKS setelah memasuki program APK.

(ii) Menilai tahap kefahaman IKS mengenai sistem pengurusan kualiti APK.

(iii) Mengkaji implikasi perlaksanaan APK terhadap pengurusan kualiti di IKS.

\subsection{METODOLOGI KAJIAN}

Untuk menjayakan dan melengkapkan kajian ini, dua pendekatan telah digunakan iaitu:

(i) Membangunkan dan menghantar satu borang kaji selidik kepada syarikatsyarikat IKS yang telah memperolehi persijilan APK.

(ii) Mengumpulkan data dengan mengkaji dan menganalisa laporan odit kualiti kilang.

Pendekatan pertama digunakan untuk mengetahui tahap kefahaman IKS mengenai sistem pengurusan APK. Borang ini terdiri daripada dua seksyen utama yang mengandungi soalan-soalan mengenai maklumat am syarikat dan sistem pengurusan kualiti. Seksyen pertama bertujuan untuk mengetahui nama dan alamat syarikat, nama dan jawatan responden, tarikh mula beroperasi, jenis pemegang saham, jenis pasaran untuk produk yang dikeluarkan, bilangan pekerja sepenuh masa, nilai jualan tahunan dan jenis industri. Seksyen kedua bertujuan untuk mengetahui tarikh mendapat persijilan APK, sijil-sijil pengurusan kualiti yang diperolehi selain APK, jangka masa yang diambil dan faktor pendorong untuk mendapatkan persijilan, jabatan yang menguruskan aktiviti peningkatan kualiti, aktiviti-aktiviti kualiti yang diamalkan oleh syarikat, faedah dan halangan 
melaksanakan skim APK, faktor kejayaan pelaksanaan skim APK, dan menilai tahap kefahaman syarikat IKS terhadap keperluan APK.

Penilaian tahap kefahaman terhadap sistem pengurusan kualiti ke atas syarikat IKS dibahagikan kepada empat kategori tanggungjawab iaitu: pengurusan, pengurusan sumber, pengurusan proses, pengukuran, analisis dan peningkatan seperti yang ditunjukkan di Jadual 2. Jadual 3 pula menunjukkan sistem gred yang digunakan untuk menilai tahap kefahaman terhadap sistem pengurusan kualiti di IKS.

Jadual 2 Keperluan amalan peningkatan kualiti mengikut kategori penilaian

\begin{tabular}{|c|c|}
\hline Kategori & Keperluan Amalan Peningkatan Kualiti \\
\hline 1. Tanggungjawab pengurusan & $\begin{array}{l}\text { a. Tanggungjawab pengurusan } \\
\text { b. Sistem kualiti } \\
\text { c. Kawalan dokumen dan data } \\
\text { d. Kawalan rekod kualiti }\end{array}$ \\
\hline 2. Pengurusan sumber & a. Latihan \\
\hline 3. Pengurusan proses & $\begin{array}{ll}\text { a. Pembelian } \\
\text { b. Pengenalan dan kebolehcarian produk } \\
\text { c. Kawalan proses } \\
\text { d. Pemeriksaan dan pengujian } \\
\text { e. Kawalan produk yang tidak menepati spesifikasi } \\
\text { f. Pengendalian, penyimpanan, pembungkusan, } \\
& \text { pemeliharaan dan penghantaran }\end{array}$ \\
\hline $\begin{array}{l}\text { 4. Pengukuran, analisis dan } \\
\text { peningkatan }\end{array}$ & a. Tindakan pembetulan dan pencegahan \\
\hline
\end{tabular}

Jadual 3 Skala likert yang digunakan di dalam borang kaji selidik dan analisa penilaian

\begin{tabular}{|c|c|c|}
\hline Gred kuantitatif & Gred kualitatif & $\begin{array}{c}\text { Peratus pengamalan } \\
\text { sistem kualiti APK }\end{array}$ \\
\hline 5 & Cemerlang & $>80 \%$ \\
4 & Baik & $65-80 \%$ \\
3 & Memuaskan & $50-64 \%$ \\
2 & Kurang memuaskan & $40-49 \%$ \\
1 & Lemah & $<40 \%$ \\
\hline
\end{tabular}

Pendekatan kedua digunakan untuk mengumpulkan data melalui laporan odit kualiti kilang (odit dilakukan untuk menentukan sama ada syarikat telah memenuhi keperluan-keperluan piawai skim APK), sumber-sumber sekunder yang lain dalam bentuk laporan dan analisa kajiselidik, dan juga menjalankan sesi temubual dengan eksekutif projek yang terlibat dalam pelaksanaan APK untuk mendapatkan maklumbalas secara terperinci. 


\subsection{KEPUTUSAN KAJI SELIDIK}

Borang kaji selidik telah dihantar kepada 100 buah syarikat IKS yang terlibat di dalam industri perkayuan (40), makanan (20), fabrikasi logam (20), plastik (10) dan lain-lain (10). Syarikat-syarikat ini telah memperolehi sijil APK melalui SIRIM Berhad. Kajian ini telah dijalankan selama enam bulan mulai Februari 2000 hingga Julai 2000 di Wilayah Persekutuan Kuala Lumpur, Selangor, Perak dan Negeri Sembilan. Bilangan responden yang telah menjawab kajiselidik ini ialah 26 buah syarikat dan pecahan mengikut jenis industri ialah seperti yang ditunjukkan dalam Rajah 2. Ia menunjukkan lebih dua pertiga (iaitu 69.3\%) daripada syarikat-syarikat IKS yang mengambil bahagian dalam kajian ini terlibat di dalam industri perkayuan. Ini terjadi disebabkan oleh bilangan syarikat IKS yang besar terlibat di dalam industri perkayuan, terutamanya dalam aktiviti membuat perabot, bilangan borang kajiselidik yang dihantar dan juga peratusan responden yang tinggi daripada industri perkayuan.

Dari segi pasaran, majoriti responden adalah terdiri dari pembekal-pembekal Guthrie Furniture Sdn Bhd (GFSB) iaitu 62\%, pasaran terbuka pada 19\%, Kementerian Kewangan pada 15\% dan Besta Distributers Sdn Bhd (BDSB) pada 4\% (sila rujuk Rajah 3).

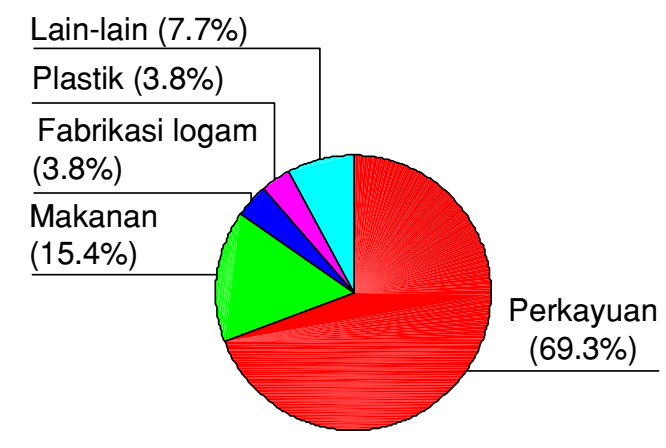

Rajah 2 Responden mengikut jenis industri

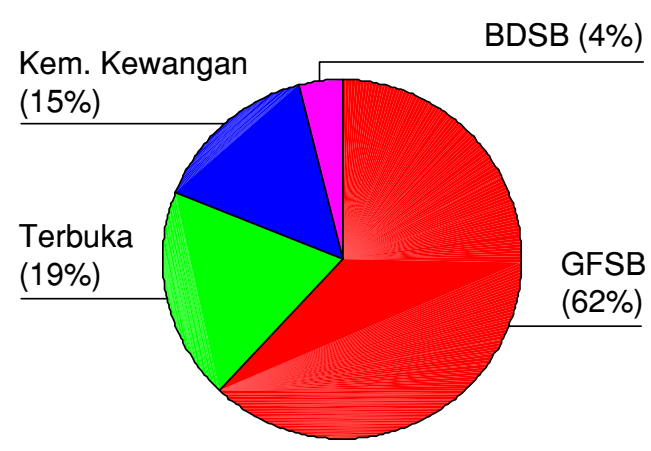

Rajah 3 Responden mengikut jenis pasaran

Rajah 4 menunjukkan 73\% responden mempunyai bilangan pekerja sepenuh masa kurang dari 50 orang. Selebihnya iaitu $27 \%$ terdiri dari syarikat bersaiz sederhana yang mempunyai bilangan pekerja di antara 50 orang hingga 150 orang. Ini bermakna kebanyakan syarikat IKS yang terlibat dalam kajian ini terdiri daripada syarikat-syarikat yang bersaiz kecil (mengikuti definisi yang dikeluarkan oleh SMIDEC pada tahun 1998).

Manakala, Rajah 5 memaparkan masa yang diambil oleh responden untuk mendapatkan sijil APK. Ia menunjukkan lebih dua pertiga (69\%) dari responden melaporkan proses untuk memperolehi sijil APK mengambil masa 18 bulan atau kurang, 15\% di antara 19 bulan hingga 24 bulan dan 16\% lebih dari 24 bulan. Berdasarkan fakta di atas, kesimpulan yang dapat diambil adalah, kebanyakan syarikat mengambil masa kurang daripada 18 bulan untuk mendapatkan persijilan APK. 
Sederhana

(27\%)

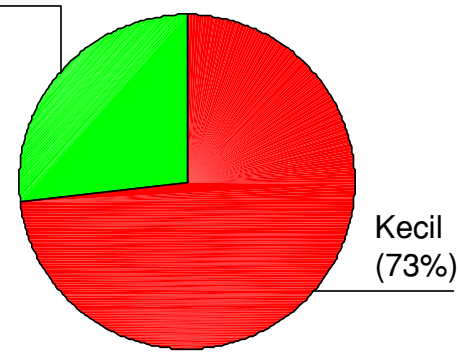

Rajah 4 Peratusan responden mengikut bilangan pekerja

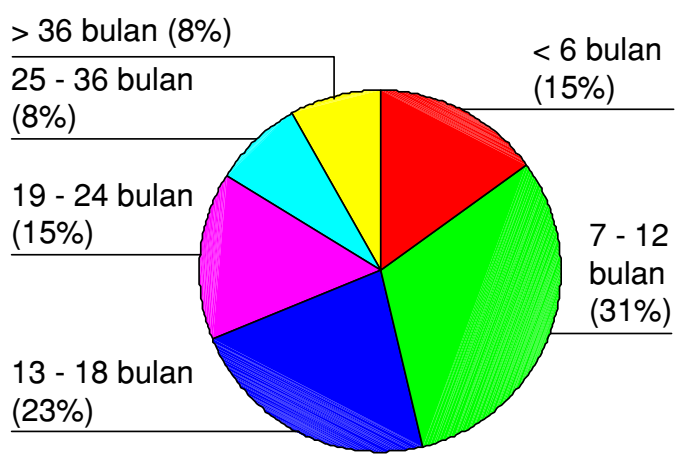

Rajah 5 Masa yang diambil oleh responden untuk mendapat Sijil APK

\subsection{PERBINCANGAN UNTUK KAJISELIDIK}

Jadual 4 menunjukkan penilaian keseluruhan responden terhadap sistem pengurusan kualiti. Gambaran yang lebih jelas boleh dirujuk pada Rajah 6, 7, 8 dan 9.

Jadual 4 Penilaian keseluruhan IKS terhadap sistem pengurusan kualiti

\begin{tabular}{|c|c|c|c|c|}
\hline $\begin{array}{c}\text { Kategori/Gred } \\
\text { Penilaian }\end{array}$ & $\begin{array}{c}\text { Tanggung- } \\
\text { jawab } \\
\text { Pengurusan } \\
\text { (TP) }\end{array}$ & $\begin{array}{c}\text { Pengurusan } \\
\text { Sumber } \\
\text { (PS) }\end{array}$ & $\begin{array}{c}\text { Pengurusan } \\
\text { Proses } \\
\text { (PP) }\end{array}$ & $\begin{array}{c}\text { Pengurusan } \\
\text { Pengukuran, } \\
\text { Analisa \& } \\
\text { Peningkatan } \\
\text { (PPAP) }\end{array}$ \\
\hline Cemerlang & $11 \%$ & $4 \%$ & $7 \%$ & $8 \%$ \\
\hline Baik & $46 \%$ & $31 \%$ & $35 \%$ & $38 \%$ \\
\hline Memuaskan & $35 \%$ & $38 \%$ & $52 \%$ & $46 \%$ \\
\hline Kurang memuaskan & $6 \%$ & $23 \%$ & $5 \%$ & $8 \%$ \\
\hline Lemah & $2 \%$ & $4 \%$ & $1 \%$ & $0 \%$ \\
\hline
\end{tabular}

Merujuk kepada Jadual 4 dan Rajah 6, data kajian untuk kategori tanggungjawab pengurusan terhadap keperluan-keperluan APK (iaitu sistem kualiti, kawalan dokumen dan data, kawalan rekod dan kualiti) menunjukkan hanya 57\% yang menyertai program APK telah memahaminya dengan baik dan cemerlang. Selebihnya iaitu $43 \%$ masih mempunyai tahap pemahaman yang lemah, kurang memuaskan dan memuaskan, mengenai kepentingan tanggungjawab pengurusan dalam melaksanakan sistem pengurusan kualiti. Dalam lain perkataan, data yang diperolehi dari kajiselidik ini menunjukkan bahawa masih terdapat ramai anggota pengurusan IKS yang perlu meningkatkan lagi kefahaman mereka terhadap keperluan-keperluan APK dan menerajui syarikat mereka ke era yang lebih mementingkan kualiti. 


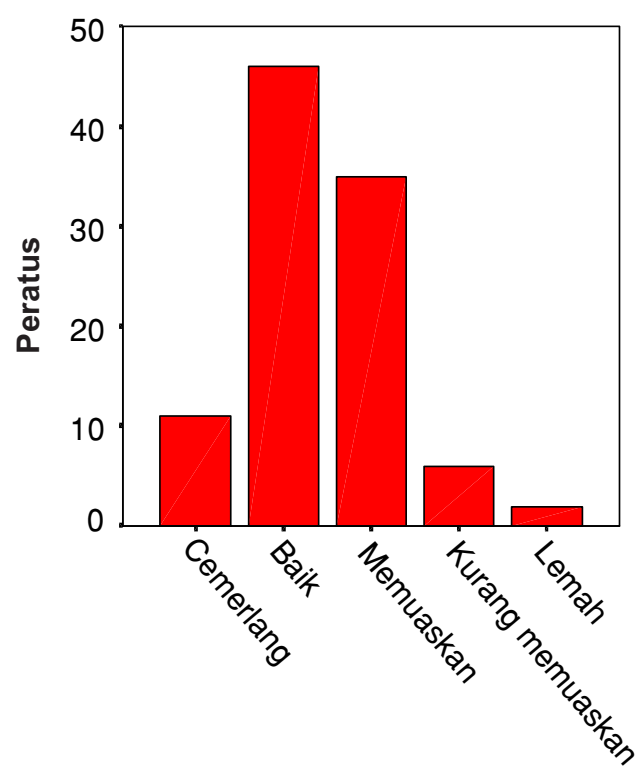

Rajah 6 Tanggungjawab pengurusan

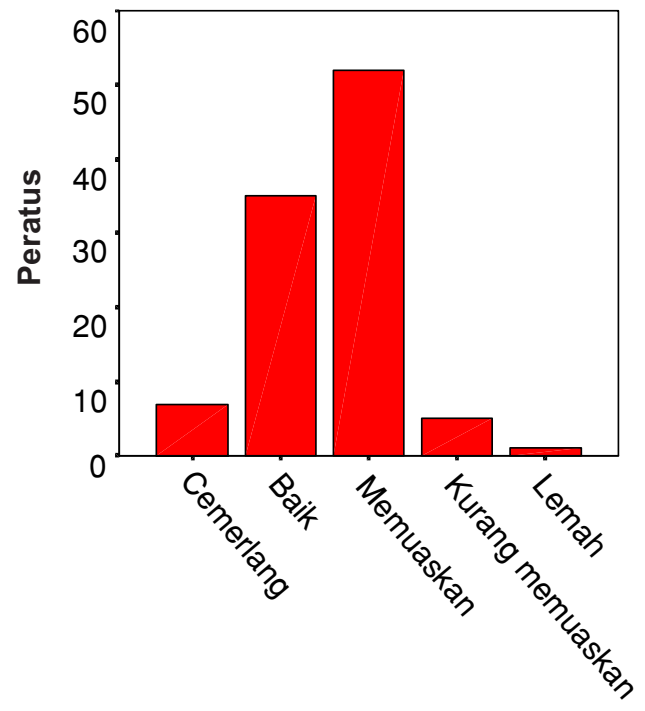

Rajah 8 Pengurusan proses

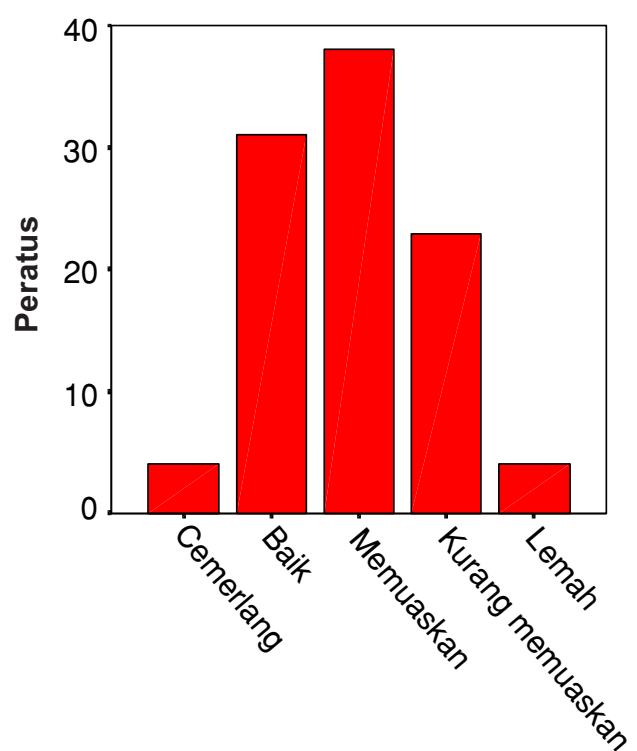

Rajah 7 Pengurusan sumber

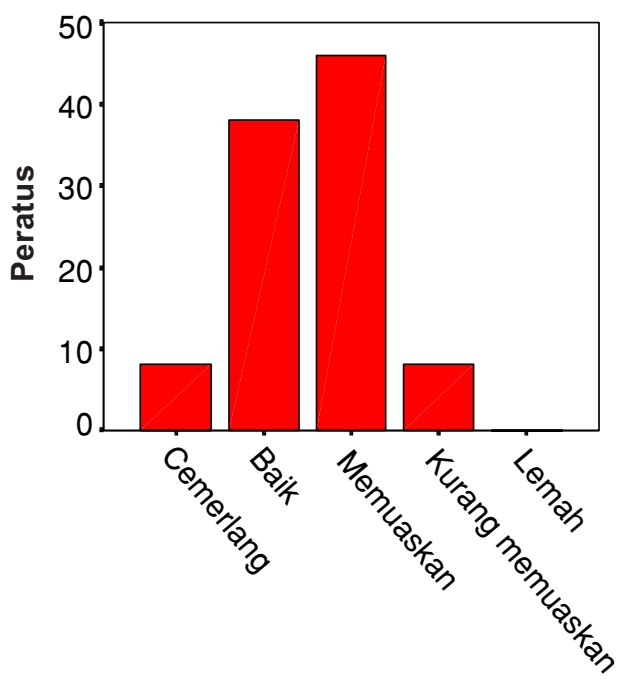

Rajah 9 Pengurusan pengukuran, analisis peningkatan

Merujuk kepada Jadual 4 dan Rajah 7, untuk kategori tanggungjawab pengurusan sumber (iaitu latihan), 4\% daripada responden mempunyai tahap kefahaman yang cemerlang, diikuti dengan 31\% pada tahap baik dan 38\% pada tahap memuaskan, 23\% pada tahap kurang memuaskan dan $4 \%$ pada tahap lemah. Hasil kajian ini menunjukkan bahawa masih terdapat $65 \%$ daripada responden yang masih belum memahami keperluan latihan untuk para pekerja dengan baik dan cemerlang. 
Seterusnya, merujuk kepada Jadual 4 dan Rajah 8, untuk kategori tanggungjawab pengurusan proses (iaitu pembelian, pengenalan dan kebolehcarian produk, kawalan proses, pemeriksaan dan pengujian, status pemeriksaan dan pengujian, kawalan produk yang tidak menepati spesifikasi, pengendalian, penyimpanan, pembungkusan, pemeliharaan dan penghantaran), 7\% daripada responden telah berada di tahap cemerlang, 35\% pada tahap baik, 52\% pada tahap memuaskan, 5\% pada tahap kurang memuaskan dan 1\% pada tahap lemah. Ini bermakna masih ramai pihak pengurusan IKS (iaitu 58\%) perlu meningkatkan lagi kefahaman mereka mengenai cara pengurusan atau kaedah perniagaan agar menjadi lebih baik dan cemerlang.

Akhirnya, merujuk kepada Jadual 4 dan Rajah 9, untuk kategori tanggungjawab pengurusan pengukuran, analisa dan peningkatan (iaitu tindakan pembetulan dan pencegahan), 8\% daripada responden telah berada di tahap cemerlang, 38\% pada tahap baik, $46 \%$ pada tahap memuaskan dan $8 \%$ pada tahap kurang memuaskan. Hasil kajian ini menunjukkan bahawa masih ramai pihak pengurusan di IKS (iaitu 54\%) yang perlu meningkatkan lagi pengetahuan dan peranan mereka dalam aktiviti pembetulan dan pencegahan agar dapat meningkat ke tahap yang lebih baik dan cemerlang.

\subsection{HASIL KAJIAN DARI SUMBER SEKUNDER}

Pengumpulan data dari sumber sekunder telah dijalankan berdasarkan kepada pengkalan data yang terdapat di Jabatan Pembangunan IKS, SIRIM Berhad. Sebanyak 70 buah syarikat yang terdiri daripada pelbagai industri telah dipilih untuk tujuan pengumpulan data. Industri perkayuan mewakili industri yang terbesar iaitu 54\%, diikuti oleh industri makanan pada 27\%, fabrikasi logam pada $6 \%$, elektronik dan plastik pada $3 \%$ dan lain-lain pada $10 \%$. Rajah 10 menunjukkan peratusan syarikat mengikut jenis industri.

Dari segi pasaran pula, lebih daripada 50\% syarikat yang terpilih adalah merupakan pembekal kepada Guthrie Furniture Sdn Bhd (GFSB), 20\% daripada Besta Distributors Sdn Bhd (BDSB), 16\% daripada Kementerian Kewangan dan 11\% memasarkan produk mereka di pasaran terbuka (sila rujuk Rajah 11).

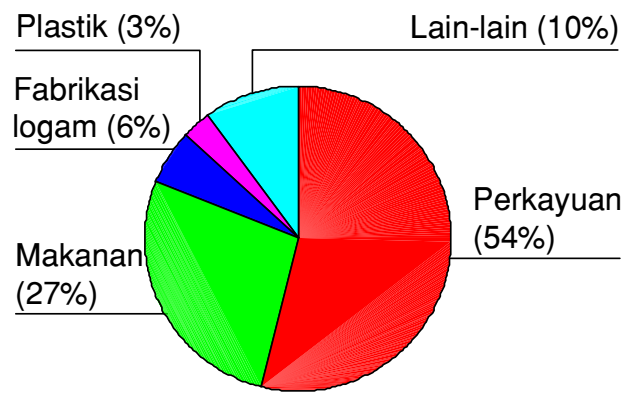

Rajah 10 Syarikat mengikut jenis industri

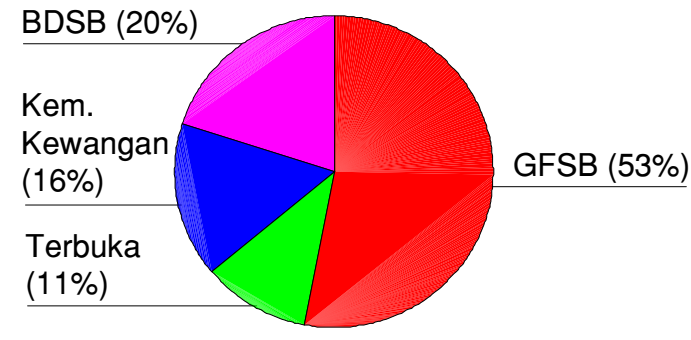

Rajah 11 Syarikat mengikut jenis pasaran 
Jika dilihat dari segi bilangan pekerja, 85\% daripada syarikat-syarikat tersebut mempunyai bilangan pekerja kurang daripada 50 orang, manakala yang selebihnya (15\%) mempunyai di antara 50 orang hingga 150 orang pekerja (sila rujuk Rajah 12). Jadi bolehlah dikatakan bahawa majoriti syarikat-syarikat itu terdiri dari kategori syarikat bersaiz kecil dan hanya sebahagian kecil yang bersaiz sederhana.

Merujuk kepada Rajah 13, kurang dari separuh (41\%) syarikat berjaya mendapatkan sijil APK dalam tempoh 24 bulan, 38\% di antara 25 bulan hingga 36 bulan, 16\% di antara 37 hingga 48 bulan dan 5\% lebih daripada 48 bulan.

Sederhana (15\%)

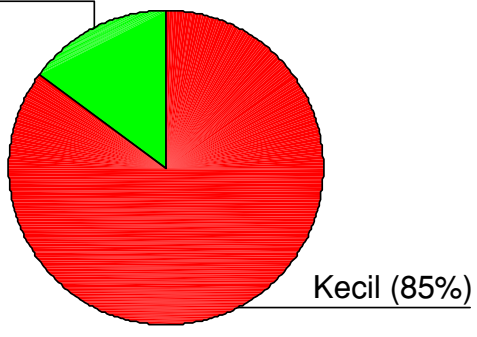

Rajah 12 Peratusan syarikat mengikut bilangan pekerja

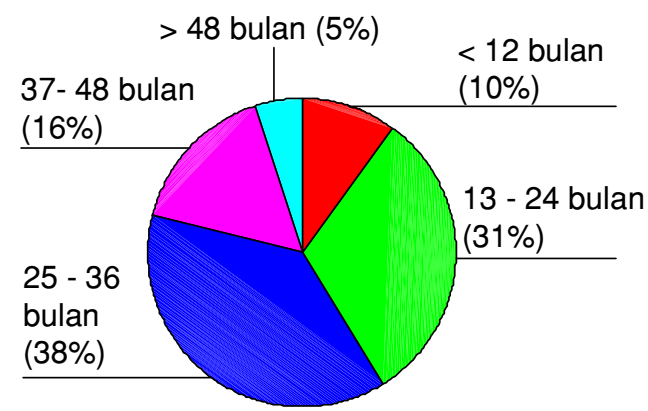

Rajah 13 Masa yang diambil oleh syarikat untuk mendapat sijil APK

\subsection{PERBINCANGAN UNTUK SUMBER SEKUNDER}

Jadual 5 menunjukkan penilaian keseluruhan responden terhadap sistem pengurusan kualiti. Sistem gred yang digunakan untuk tujuan penilaian ini adalah sama seperti yang telah digunakan dalam kaji selidik secara pos. Gred ini diperolehi daripada laporan pengesyoran sijil APK oleh SIRIM Berhad.

Jadual 5 Penilaian keseluruhan IKS terhadap sistem pengurusan kualiti

\begin{tabular}{|c|c|c|c|c|}
\hline $\begin{array}{c}\text { Kategori/Gred } \\
\text { Penilaian }\end{array}$ & $\begin{array}{c}\text { Tanggung- } \\
\text { jawab } \\
\text { Pengurusan } \\
\text { (TP) }\end{array}$ & $\begin{array}{c}\text { Pengurusan } \\
\text { Sumber } \\
\text { (PS) }\end{array}$ & $\begin{array}{c}\text { Pengurusan } \\
\text { Proses } \\
\text { (PP) }\end{array}$ & $\begin{array}{c}\text { Pengukusan } \\
\text { Analisa \& } \\
\text { Peningkatan } \\
\text { (PPAP) }\end{array}$ \\
\hline Cemerlang & $11 \%$ & $3 \%$ & $8 \%$ & $2 \%$ \\
\hline Baik & $63 \%$ & $27 \%$ & $60 \%$ & $64 \%$ \\
\hline Memuaskan & $26 \%$ & $70 \%$ & $32 \%$ & $34 \%$ \\
\hline Kurang memuaskan & $0 \%$ & $0 \%$ & $0 \%$ & $0 \%$ \\
\hline Lemah & $0 \%$ & $0 \%$ & $0 \%$ & $0 \%$ \\
\hline
\end{tabular}


Rajah 14 memaparkan penemuan kajian yang menunjukkan pada keseluruhannya hanya $11 \%$ daripada syarikat yang dinilai mempunyai tanggungjawab pengurusan di tahap cemerlang, manakala majoritinya (63\%) berada di tahap baik dan selebihnya (26\%) di tahap memuaskan. Ini bermakna majoriti IKS masih lagi belum melaksanakan tanggungjawab pengurusan dengan cemerlang. Sebagai contoh, masih terdapat kakitangan syarikat yang belum memahami polisi dan objektif kualiti syarikat, senarai tugas tidak didokumen dan pihak pengurusan syarikat tidak melaksanakan semakan terhadap sistem kualiti yang diwujudkan.

Merujuk kepada Rajah 15, hanya 3\% daripada syarikat yang dinilai mempunyai pengurusan sumber (sebagai contoh, program latihan) yang cemerlang, 27\% syarikat di tahap yang baik dan selebihnya (70\%) mempunyai pasukan pengurusan yang memuaskan. Data kajian telah menunjukkan IKS kurang memberi perhatian di dalam usaha untuk menyediakan program pembangunan sumber manusia di syarikat mereka dan tidak menyediakan peruntukan yang sewajarnya di dalam sistem pengurusan kualiti. Ini adalah penting kerana pemahaman dan kesedaran kakitangan terhadap peranan sistem pengurusan kualiti akan menentukan sama ada program kualiti itu berjaya atau gagal dalam pelaksanaannya.

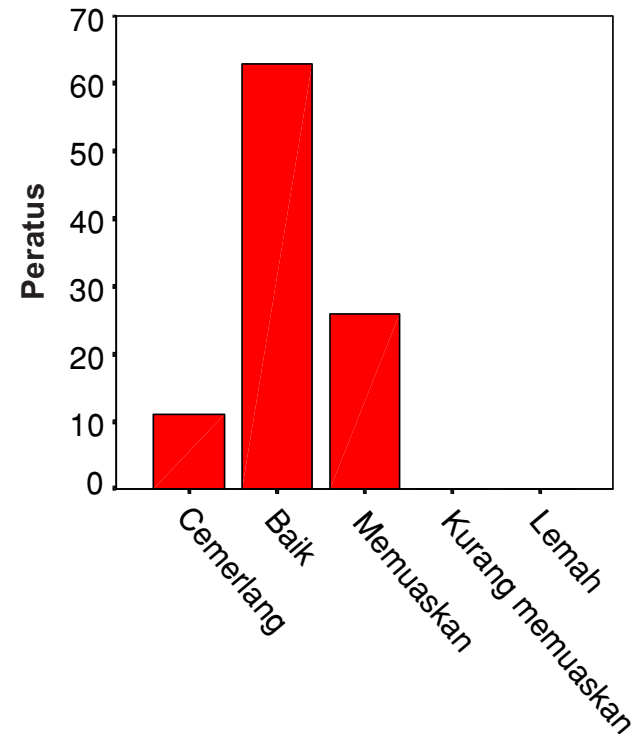

Rajah 14 Tanggungjawab pengurusan

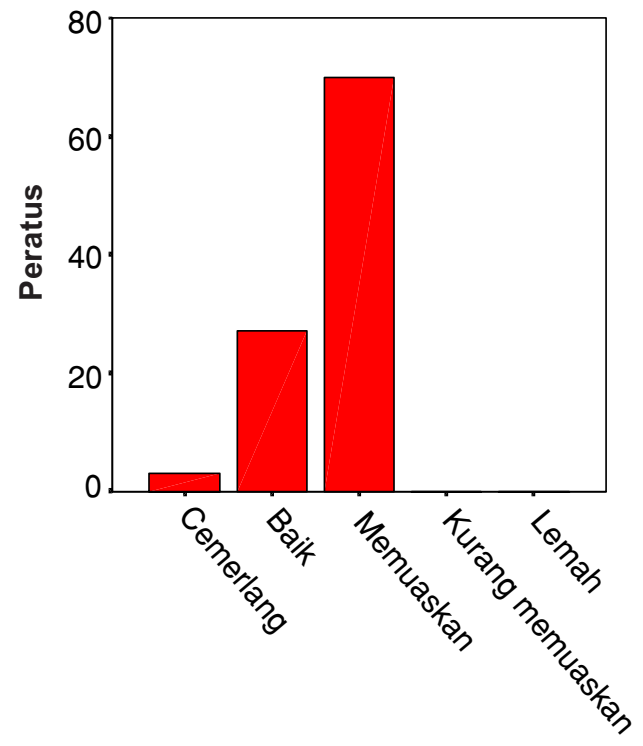

Rajah 15 Pengurusan sumber

Rajah 16 menunjukkan hanya 8\% syarikat yang dinilai mempunyai tahap pengurusan proses yang cemerlang, $60 \%$ pada tahap baik dan selebihnya masih berada di tahap memuaskan walaupun telah mengikuti program APK. Menurut pemerhatian penulis pada keseluruhannya, IKS masih boleh mempertingkatkan lagi tahap kecekapan pengurusan proses mereka kepada tahap cemerlang. Ini penting kerana pengurusan 


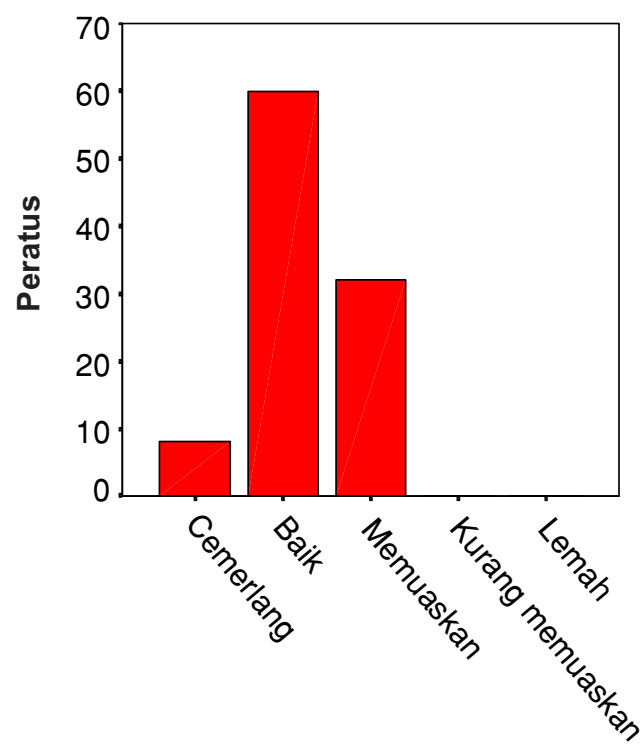

Rajah 16 Pengurusan proses

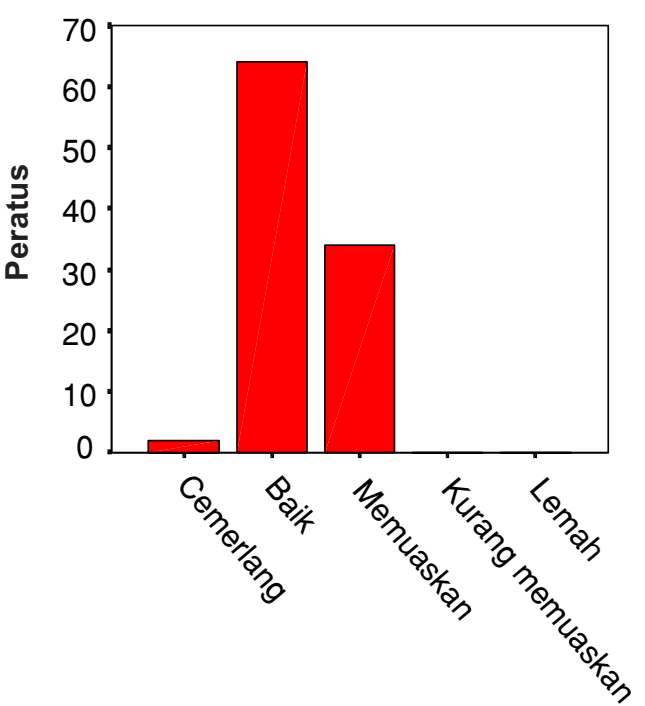

Rajah 17 Pengurusan pengukuran, analisis \& peningkatan

proses yang lebih cekap dan efisen akan dapat meningkatkan kualiti dan mengurangkan kos serta masa pemprosesan.

Secara keseluruhan bagi kategori pengurusan, penganalisaan dan peningkatan seperti yang dipaparkan oleh Rajah 17, hanya $2 \%$ syarikat yang dinilai mempraktikkannya dengan cemerlang, manakala $64 \%$ pada tahap baik dan 34\% berada di tahap memuaskan. Sebagai contoh, sebilangan besar syarikat IKS merekodkan aduan pelanggan tetapi tiada tindakan susulan dibuat seperti menyiasat punca-punca masalah dan juga tiada tindakan pembetulan dan pencegahan dilaksanakan.

\subsection{PERBANDINGAN KEPUTUSAN KAJI SELIDIK DAN SUMBER SEKUNDER}

Secara umumnya, hasil penemuan menerusi kaji selidik dan sumber sekunder adalah selari dari segi latar belakang responden mengikut jenis industri, pasaran dan bilangan pekerja. Walau bagaimanapun, terdapat sedikit perbezaan dari segi masa yang diambil oleh syarikat-syarikat IKS yang terlibat di dalam kaji selidik dan sumber sekunder. Ini kerana lebih daripada dua-pertiga (69\%) syarikat IKS yang terlibat dalam kaji selidik telah berjaya memperolehi sijil APK dalam tempoh 18 bulan ataupun kurang, manakala kurang daripada separuh (41\%) syarikat yang terpilih daripada sumber sekunder memperolehi sijil APK dalam tempoh kurang daripada 24 bulan.

Penilaian keseluruhan IKS terhadap sistem pengurusan kualiti dalam keempatempat aspek pengurusan (iaitu tanggungjawab pengurusan, pengurusan sumber, pengurusan proses, dan pengurusan pengukuran, analisa dan peningkatan) adalah 
lebih baik (iaitu termasuk dalam 3 gred: cemerlang, baik dan memuaskan). Menurut sumber sekunder, ini adalah berbanding dengan kaedah kaji selidik yang mempunyai 5 gred (cemerlang, baik, memuaskan, kurang memuaskan dan lemah). Walau bagaimanapun, penulis ingin menegaskan di sini bahawa sumber sekunder dalam kajian ini hanya menunjukkan data syarikat IKS yang telah berjaya dalam usaha mereka untuk mendapat sijil APK daripada SIRIM. Ini kerana untuk mendapatkan sijil APK, mereka mestilah sekurang-kurangnya mencapai tahap memuaskan dalam pemakaian sistem pengurusan kualiti APK. Manakala, hasil kajian yang diperolehi dari kaji selidik pula menunjukkan tahap sebenar pemakaian atau pengamalan sistem peningkatan kualiti APK di syarikat-syarikat IKS setelah mereka memperolehi sijil APK.

Maka, hasil kaji selidik secara pos dan sumber sekunder menunjukkan bahawa kebanyakan syarikat IKS tidak mempertingkatkan lagi tahap pengamalan sistem pengurusan kualiti APK setelah mereka mendapat sijil APK daripada SIRIM. Ini dapat dibuktikan melalui kaji selidik secara pos dan sumber sekunder. Oleh itu, untuk terus maju, lebih kompetitif dan berdaya saing di dalam pasaran yang kompetitif, IKS perlulah meningkatkan lagi tahap pemakaian sistem pengurusan kualiti keperingkat yang lebih baik dan cemerlang.

\subsection{PERBINCANGAN KESELURUHAN DAN KESIMPULAN}

Hasil kajian ini menunjukkan bahawa kebanyakan IKS masih belum lagi berada di tahap yang baik dan cemerlang untuk keempat-empat kategori di dalam sistem pengurusan untuk amalan peningkatan kualiti (APK). Jadi boleh dikatakan, majoriti pihak pengurusan di IKS yang telah menyertai program APK ini masih belum memahami peranan dan tanggungjawab mereka di dalam melaksanakan sistem pengurusan kualiti. Data kajian menunjukkan hanya 11\% daripada syarikat IKS yang memahami dengan cemerlang akan peranan pihak pengurusan dalam melaksanakan amalan peningkatan kualiti di organisasi masing-masing. Untuk meningkatkan lagi daya saing IKS di peringkat antarabangsa dan global, pengurusan IKS perlulah berusaha untuk meningkatkan peranan dan komitmen mereka mengenai kualiti dan mengamalkannya dengan lebih meluas.

Untuk mengeluarkan produk dan servis yang berkualiti dan kompetitif di pasaran global, IKS perlu menerap dan memupuk kesedaran serta mengamalkan budaya peningkatan kualiti di semua peringkat organisasi. Ia mestilah melibatkan semua pekerja dari pengurusan atasan sehinggalah ke peringkat bawahan seperti operator pengeluaran. Di antara langkah-langkah yang boleh diambil untuk meningkatkan kesedaran ialah dengan mengadakan sesi penerangan, kempen, latihan, kursus dan menjadikan kualiti sebahagian daripada agenda utama perbincangan atau mesyuarat mingguan dan bulanan syarikat.

Hasil kajian menunjukkan bahawa tahap kefahaman pihak pengurusan di IKS terhadap sistem pengurusan kualiti perlu dipertingkatkan lagi. Ini kerana, tahap 
kefahaman mereka mengenai pengurusan kualiti masih lagi berada di tahap rendah walaupun setelah menyertai program APK. Ini mungkin berlaku disebabkan oleh sikap mereka yang memandang ringan peranan dan sumbangan sistem pengurusan kualiti terhadap pengendalian syarikat dan juga tidak mahu mempraktikkan dengan bersungguh-sungguh ilmu pengetahuan yang telah dipelajari semasa mengikuti program APK.

Komitmen dan kesungguhan dari pihak pengurusan atasan perlu dibuktikan melalui lisan dan amalan. Pihak pengurusan atasan perlu terlebih dahulu memahami kepentingan sistem kualiti di dalam organisasi mereka. Tanpa kefahaman dan kesedaran ini adalah sukar untuk memberi komitmen dan kesungguhan dalam mencapai polisi dan objektif pengurusan kualiti. Penelitian yang boleh dibuat berdasarkan kajian di atas menunjukkan bahawa tahap kefahaman dan pengamalan IKS terhadap sistem pengurusan kualiti masih lagi lemah dan perlu dipertingkatkan supaya IKS mempunyai daya saing yang lebih baik di peringkat nasional dan antarabangsa.

\section{RUJUKAN}

[1] Heizer, J., dan B. Render. 1993. Production and Operation Management. $3^{\text {rd }}$ Edition. Boston: Allyn and Bacon.

[2] Hashim, A. G. M. 1999. Kursus Apresiasi dan Dokumentasi Sistem Pengurusan Kualiti. Nota Kursus: Jabatan Pembangunan IKS. SIRIM Berhad.

[3] Idris, M. A., dan S. Idris. 1996. Kajian Ke Atas Pengamalan Skim Amalan Peningkatan Kualiti (APK). Laporan Teknik. Jabatan Pembangunan IKS. SIRIM Berhad.

[4] Aziz, Z. A., J. F. Chan., dan A. D. Metcalfe. 1998. Use of Quality Practices in Manufacturing Industries in Malaysia. Total Quality Management. 9(4 \& 5): 13-16.

[5] Musa, A. 1997. The Status of Productivity and Quality Improvement Techniques Which has Been Practiced Within Malaysian Industries and Services Companies. Proceedings of the International Conference on Quality Control Circles (ICQCC, 1997). 147-159.

[6] Rahman, S. 2001. A Comparative Study of TQM Practice and Organisational Performance of SMEs With and Without ISO 9000 Certification. International Journal of Quality E Reliability Management. 18(1): 35-49.

[7] Hashim, M. K., dan S. A. Wafa. 2002. Small \& Medium Sized Enterprises in Malaysia - Development Issues. Malaysia: Prentice Hall.

[8] Yusof, S.M. 2000. Development of a Framework for TQM Implementation in Small Business. PhD Thesis. Faculty of Engineering. University of Birmingham. U.K.

[9] Anthony, D. 1983. Japan. In D. J. Storey (ed.). The Small Firms: An International Survey. Croom Helm, London. 46-83.

[10] Small and Medium Sized Industries Development Corporation (SMIDEC). 1998. Perbadanan Kemajuan Industri Kecil dan Sederhana. Malaysia.

[11] Hall, C. 1995. APEC and SME POLICY: Suggestions for an Action Agenda, Australian APEC Study Centre, Issues Paper No. 1, (URL) http://www. arts.monash.edu.au/auspec/iss1.htm.

[12] Sevilla, R. C., dan K. Soonthornthada. 2000. SME Policy in Thailand: Vision and Challenges. Institute for Population and Social Research. Mahidol University. Salaya Campus. Nakhon Pathom. Thailand.

[13] Storey, D. J. 1994. (ed.). Understanding the Small Business Sector. London: Rutledge.

[14] Ghobadian, A., dan D. N. Gallear. 1996. Total Quality Management in SMEs. Omega, International Journal Management Science. 24(1): 83-106.

[15] Husband, S., dan P. Mandal. 1999. A Conceptual Model for Quality Integrated Management in Small And Medium Size Enterprises. International Journal of Quality \&ै Reliability Management. 16(7): 699-713. 
[16] SMI Business Directory. 2002. The Official Business Directory of SMI Association of Malaysia.

[17] Shan, S. 2000. IKS Tetap Handal, Malaysian Enterprise. Mac. 54-55.

[18] Malaysia.1999. Kajian Separuh Penggal Rancangan Malaysia Ketujuh (1996 - 2000). Kuala Lumpur: Percetakan Nasional Malaysia Berhad.

[19] Kim S. J., dan J. W. Suh 1991. Cooperation in Small and Medium - Scale Industries in ASEAN. Asia and Pacific Development Centre. 9-28.

[20] Hashim, M. K. 2000. SMEs in Malaysia: Past, Present and Future. Malaysian Management Revierw. June 2000 .

[21] SMI Development Plan. 2002. Perbadanan Kemajuan Industri Kecil dan Sederhana, Malaysia.

[22] Greenan K., P. Humphreys., dan R. McIvor. 1997. The Green Initiative: Improving Quality and Competitiveness for European SMEs. European Business Review. 97(5): 208-214.

[23] Idris, M. A. 1997. A Total Quality Management Implementation Model for Small and Medium Sized Manufacturing Industries. PhD Thesis. University of Paisley. Quality Centre. Scotland.

[24] Othong, S. 2000. Pelaksanaan Sistem Pengurusan Kualiti di Industri Kecil dan Sederhana (IKS). Thesis MSc. Fakulti Kejuruteraan, Universiti Kebangsaan Malaysia.

[25] Marzuki, K. S. 1998. Bengkel Dokumentasi Sistem Kualiti Skim Amalan Peningkatan Kualiti. Nota Kursus. Jabatan Pembangunan IKS. SIRIM Berhad. 